\title{
Keragaman arthropoda herbivora dan musuh alami pada tanaman padi lahan rawa di Rowopulo Kecamatan Gumukmas Kabupaten Jember
}

\author{
Diversity of herbivorous arthropods and natural enemies in swamp rice plant in \\ Rowopulo-Gumukmas Jember district
}

\author{
Muflih Adnan ${ }^{1}$ dan Wagiyana ${ }^{1^{*}}$ \\ ${ }^{1}$ Fakultas Pertanian, Universitas Jember. Jl. Kalimantan 37 Kampus Tegalboto Jember 68121
}

INFORMASI ARTIKEL

\author{
*Korespondensi: \\ Wagiyana \\ wagiyana@gmail.com \\ Informasi proses: \\ Received: 4 November 2019 \\ Accepted: 5 Januari 2020 \\ Published: 16 Januari 2020
}

Cara sitasi: Adnan M, dan Wagiyana. 2020. Keragaman arthropoda herbivora dan musuh alami pada tanaman padi lahan rawa di Rowopulo Kecamatan Gumukmas Kabupaten Jember. Jurnal Proteksi Tanaman Tropis 1(1): 27-32

DOI: 10.19184/jptt.v1i1/5586

\begin{abstract}
Rowopulo is one of the swamps in Gumukmas, Jember Regency with its unique soil in the form of peat soil that floats on water and by the community used for rice cultivation, whose production is influenced by the presence of Plant Pests, which is dominated by the Herbivore Arthropods. The presence of herbivorous Arthropods in the swampland rice ecosystem can be suppressed by the presence of useful Arthropod populations such as predators, parasitoids, and pollinators. Related to this, a study was conducted to find out the diversity of Arthropods found in swampy rice plantations. The study began with a land survey, then the determination and marking of observation plots on the map and matching these locations using GPS (Global Positioning System). Observations were made on plots that were made based on the extent of rice plants that were still in one stretch and the same irrigation flow. Each plot was observed ten times at 7 -day intervals from rice plants aged 14 days after 77 days after planting. Arthropod sampling using sweep net method. Catching arthropods are put into vials of $5 \mathrm{ml}$ size and then identified up to family level, and the diversity, evenness, and wealth index of the species is calculated. The results of research on swamp rice plants contained 37 families. Ten families act as herbivorous Arthropods, 15 families as predators, six families as parasitoids, one family as pollinators, and five families as detritivores. The highest diversity index in plot 1 was 2.95 , while the lowest in plot 2 was 2.70 , with the medium category for all observation plots. The magnitude of the diversity index is due to the dominance of only a few orders, such as Orthoptera and Diptera; the highest species wealth index in plot 3 with a value of more than 4 in the high category; Evenness index of all observation plots has a value of less than 1 with uneven categories.
\end{abstract}

Keywords: arthropods; diversity; natural enemies; swamp land

\section{Pendahuluan}

Rowopulo merupakan salah satu lahan rawa yang terdapat di Kabupaten Jember dengan keunikan berupa lahan gambut yang dimanfaatkan untuk budidaya tanaman padi. Berdasarkan data Badan Pusat Statistik (BPS) tahun 2018, hasil produksi padi di Kecamatan Gumukmas pada tahun 2013 sebesar 7.941 ton, tahun 2014 yaitu 8.060 ton, sedangkan pada tahun 2015 dan 2016 produksi padi menurun menjadi 5.801 ton, dan tahun 2017 meningkat menjadi 6.467 ton. Setiap kegiatan budidaya tanaman tidak akan lepas dari adanya populasi arthropoda, baik herbivor maupun musuh alami. Keberadaan arthropoda herbivor pada lahan budidaya berpotensi menghambat serta menurunkan produksi tanaman padi. 
Jenis organisme pengganggu tanaman atau arthropoda herbivor dari hasil penelitian Yursida dan Kalsum (2015) pada tanaman padi lahan rawa di Kabupaten Banyuasin menunjukkan jenis arthropoda herbivor yang sering menyerang antara lain: kepinding tanah, belalang, kepik cokelat, hama putih, hama putih palsu, ulat penggulung daun, walang sangit, kepik hijau, wereng cokelat, dan penggerek batang.

Semua spesies hama mempunyai musuh alami (parasitoid, predator, dan patogen) yang menyerang pada berbagai variasi tingkat hidupnya. Musuh alami mempunyai peran penting dalam mengurangi populasi hama pada tanaman padi lahan rawa terutama arthropoda yang berperan sebagai predator dan parasitoid. Predator merupakan organisme yang sepanjang hidupnya hidup secara bebas, membunuh mangsanya, biasanya berukuran lebih besar daripada mangsanya, dan memerlukan lebih dari satu mangsa untuk menyelesaikan perkembangannya (Mudjiono 2013).

Populasi arthropoda dapat dijadikan sebagai spesies bioindikator ekologis dikarenakan kelompok ini sangat sensitif terhadap gejala perubahan dan tekanan lingkungan akibat aktifitas manusia atau akibat kerusakan sistem biotik (Purwantiningsih 2014). Populasi arthropoda herbivor di lahan setiap waktu mengalami masa fluktuatif, tergantung adanya arthropoda berguna seperti predator, parasitoid, dan polinator yang menjadi penghambat langsung bagi populasi arthropoda herbivor. Keanekaragaman musuh alami pada fase-fase tertentu mampu memangsa dan memparasit hama di setiap tingkatan, sehingga keberadaannya sangat berpengaruh terhadap perkembangan populasi hama serta belum adanya data penelitian terkait jenis-jenis arthropoda yag terdapat pada lahan rawa di Rowopulo Kecamatan Gumukmas Kabupaten Jember.

\section{Metode penelitian}

\section{Survei Lokasi Pengamatan}

Penentuan titik plot pengamatan dilakukan dengan melihat peta kemudian membuat titik sampai membentuk pola diagonal. Selanjutnya melakukan survei lahan dengan membawa alat Global Positioning System (GPS) dan mencocokkan titik sesuai dengan kondisi lahan. Titik koordinat tersebut menjadi plot pengamatan yang kemudian diberi papan keterangan yang ditancapkan dengan ajir, denah penelitian seperti pada Gambar 1.

Penentuan plot pengamatan dengan pola diagonal didasarkan pada letak topografi tanah tabelan yang masih dalam satu hamparan dengan bentuk oval memanjang serta aliran air irigasi yang sama.

\section{Metode Pengambilan Data}

Pengamatan dan pengambilan sampel arthropoda dengan menggunakan metode nisbi dengan bantuan jaring ayun. Pengamatan dilaksanakan dari mulai umur 14 hari setelah tanam (hst) sampai dengan $77 \mathrm{hst}$ dengan interval 7 hari. Pengamatan dilakukan pada waktu pagi dan sore hari. Teknik pengamatan dilakukan dengan menggunakan transect line yaitu dengan cara berjalan mengikuti lajur tanaman pada plot pengamatan serta menghitung jumlah serangga yang ditemukan di sepanjang jalur pengamatan (Bismark 2011).

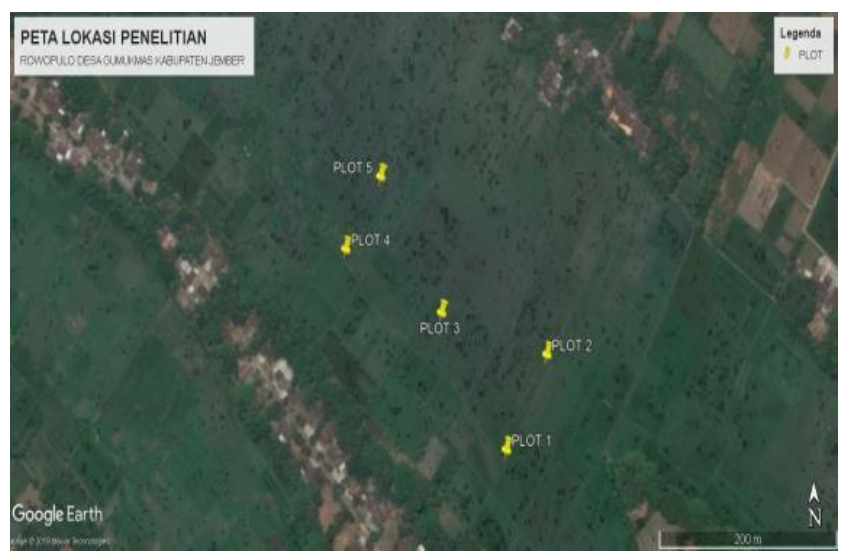

Gambar 1. Peta plot penelitian lahan Rawa di Rowopulo. (Sumber: Hasil Penandaan dengan GPS)

Pengambilan serangga dilakukan dengan sweeping atau menjaring dengan alat jaring sebanyak 10 kali ayunan ganda. Lebar ayunan selebar 1 meter dan jarak baris ayunan satu dengan berikutnya adalah $40 \mathrm{~cm}$ (Direktorat Perlindungan Tanaman Pangan 2018). Metode ini digunakan untuk menangkap serangga yang aktif terbang.

Arthropoda yang tertangkap, dimasukkan ke dalam plastik yang berisi etanol $70 \%$, kemudian dipilah berdasarkan jenis untuk dikoleksi dan didokumentasikan. Pengkoleksian serangga dilakukan dengan cara memasukkan arthropoda ke dalam botol koleksi yang berisi cairan etanol 70\% dan diberi label.

\section{Identifikasi Arthropoda}

Identifikasi arthropoda dilakukan dengan mengamati ciri fisik atau morfologinya menggunakan mikroskop sampai tingkat famili dengan melihat buku panduan identifikasi Borror dan White (1998) dan IRRI (1994). Identifikasi dengan melihat tipe kepala, toraks, dan sayap serta ciri fisik arthropoda yang kemudian dikelompokkan berdasarkan perannya sebagai herbivor, predator, parasitoid, pollinator dan detrivor.

\section{Pengolahan Data}

Kelimpahan dan diversitas arthropoda herbivor serta musuh alaminya dianalisis dengan menggunakan Indeks Shannon Wiener (H), Indeks Kemerataan Evenness (E) dan Indeks Kekayaan Margalef (R). Variabel yang diamati meliputi populasi arthropoda herbivor, musuh alami, polinator, indeks keaneka- 
ragaman, kemerataan, dan Kekayaan jenis Arthropoda pada tanamanpadi di lahan rawa.

\section{Hasil Penelitian}

\section{Populasi arthropoda di masing-masing plot pengamatan}

Populasi arthropoda selama pengamatan sebanyak 6.824 ekor. Rata-rata populasi arthropoda tertinggi terdapat pada plot 5 dengan rata-rata sebanyak 151,2 ekor pada plot 4 mencapai rata-rata 145,2 ekor (Gambar 2).

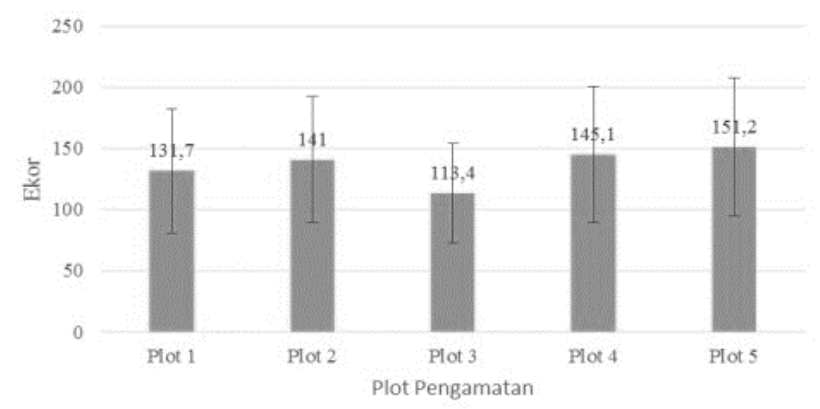

Gambar 2. Populasi arthropoda pada plot pengamatan.

Gambar 2 merupakan persentase ordo yang diperoleh pada pengamatan tanaman padi di lahan rawa usia 14 hst hingga 77 hst.

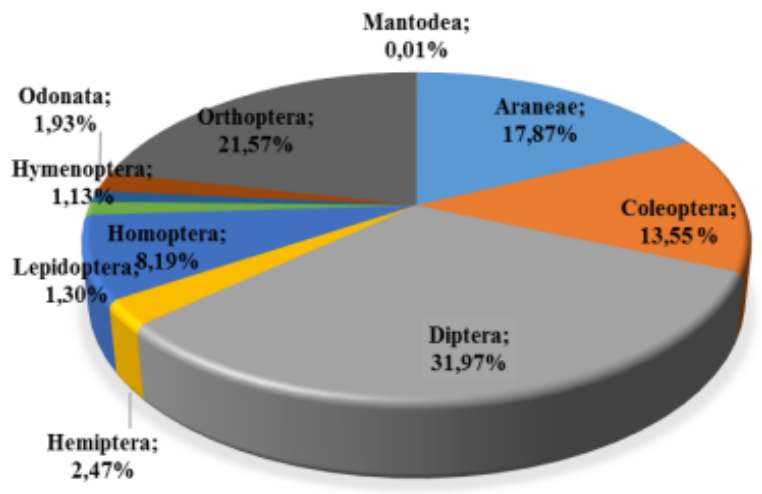

Gambar 3. Persentase populasi arthropoda berdasarkan ordo.

Hasil identifikasi semua arthropoda yang diperoleh selama pengamatan antara lain: laba-laba, ordo Coleoptera, Diptera, Hemiptera, Hymenoptera, Homoptera, Lepidoptera, Odonata, Orthoptera dan Mantodea. Berdasarkan Gambar 3 diketahui dominasi arthropoda tertinggi terdapat pada Ordo Diptera (31,97\%), Orthoptera (21,57\%), laba-laba (17,87\%), dan Coleoptera (13,55\%), sedangkan Ordo terendah yaitu Mantodea dan Lepidoptera dengan persentase berturutturut sebesar $0,01 \%$ dan $1,30 \%$.

\section{Populasi arthropoda herbivora, predator, parasitoid, polinator dan detritivor}

Populasi arthropoda herbivor dari hasil pengamatan diketahui ada 10 familia. Jumlah tersebut diketahui dari hasil identifikasi serta pengelompokan peran arthropoda tersebut pada ekosistem. Tabel 1 menunjukkan populasi kelompok herbivor pada setiap plot pengamatan.

Tabel 1. Populasi arthropoda sebagai herbivor berdasarkan famili pada plot pengamatan.

\begin{tabular}{lccccc}
\hline \multirow{2}{*}{\multicolumn{1}{c}{ Famili }} & \multicolumn{5}{c}{ Populasi herbivor tiap plot pengamatan } \\
\cline { 2 - 6 } & Plot 1 & Plot 2 & Plot 3 & Plot 4 & Plot 5 \\
\cline { 2 - 6 } Pentatomidae & 0,8 & 0,4 & 0,7 & 0,7 & 1 \\
Alydidae & 3,7 & 3,2 & 2,7 & 0,8 & 0,9 \\
Cicadellidae & 8,3 & 6,8 & 10,2 & 11,2 & 16,8 \\
Delphacidae & 0,7 & 0,3 & 0,4 & 0,9 & 0,4 \\
Crambiidae & 2 & 0,5 & 1,6 & 1,5 & 3,3 \\
Acrididae & 2,3 & 5,2 & 1,8 & 3,9 & 4 \\
Tetrigidae & 9,4 & 25,2 & 8,9 & 14 & 9,7 \\
Chrysomelidae & 1,6 & 0,7 & 0,7 & 0,8 & 1 \\
Pyrgomorphidae & 0,3 & 0 & 0,1 & 0 & 0,4 \\
Tridactylidae & 0 & 0 & 0,1 & 3,1 & 0,3 \\
\hline
\end{tabular}

Rata-rata populasi arthropoda herbivor dalam plot pengamatan di lahan rawa terdapat 10 familia dari hasil identifikasi yang diketahui berperan sebagai arthropoda herbivor. Dominansi arthropoda tertinggi terlihat pada famili tetrigidae dari Ordo Orthoptera dan Cicadellidae dari Ordo Homoptera. Sedangkan kehadiran arthropoda terendah terlihat pada golongan famili Pyrgomorphidae yang hanya ditemukan pada plot pengamatan 3 dan 5 dengan rata-rata hanya 1 dan 4 ekor selama 10 kali pengamatan.

Terdapat 14 familia yang berperan sebagai predator. Hasil menunjukkan bahwa populasi predator paling tinggi pada plot pengamatan ditunjukkan oleh famili coccinellidae pada plot 5 dengan rata-rata sebanyak 21,4 ekor selama 10 kali pengamatan, dan untuk famili yang berperan sebagai predator tertinggi kedua yang ditemukan pada plot pengamatan ditunjukkan oleh famili Tetragnathidae pada plot 2 dengan rata-rata sebanyak 11,7 ekor selama 10 kali pengamatan (Tabel 2). Kehadiran predator terendah pada kelima plot pengamatan ditunjukkan oleh famili Mantidae dari ordo Mantodea dengan kehadiran sebesar 0,1 pada plot 2 pengamatan dan famili Reduviidae dari Ordo Hemiptera dengan kehadiran sebanyak 0,1 ekor pada plot 1.

Berdasarkan hasil identifikasi famili Arthropoda yang didapat maka diketahui 6 familia yang berperan sebagai parasitoid. Kelompok parasitoid, dapat diketahui pada kelima plot pengamatan populasi parasitoid tertinggi terdapat pada famili Pipunculidae (Tabel 3). 
Hasil identifikasi Arthropoda yang berperan sebagai polinator ditemukan 1 famili dari ordo Diptera yaitu famili Anthomyzidae yang ditemukan paling banyak di plot 3 dengan rata-rata 1,8 dan paling rendah di plot 5 dengan rata-rata 0,1 selama 10 kali pengamatan. Ratarata arthropoda sebagai detritivor paling banyak dari famili Lauxaniidae (Tabel 4).

Tabel 2. Populasi arthropoda sebagai predator berdasarkan famili yang ditemukan di lahan pengamatan.

\begin{tabular}{llllll}
\hline \multirow{2}{*}{ Famili } & \multicolumn{5}{c}{ Populasi Predator tiap plot pengamatan (ekor) } \\
\cline { 2 - 6 } & Plot 1 & Plot 2 & Plot 3 & Plot 4 & Plot 5 \\
\hline Tetragnathidae & 12,1 & 13,7 & 11,7 & 12,8 & 10,6 \\
Linyphiidae & 5,3 & 11,6 & 9,5 & 4,3 & 5,6 \\
Oxyopidae & 0,6 & 0,7 & 0 & 0,6 & 0,9 \\
Thomisidae & 3,4 & 5,7 & 4,2 & 5,4 & 3,4 \\
Sciomyzoidae & 11,1 & 4,5 & 5,4 & 6,6 & 8,8 \\
Dolichopodidae & 1 & 0,6 & 0,6 & 0,3 & 0,1 \\
Pentatomidae & 0,4 & 0,2 & 0,3 & 0,2 & 0,3 \\
Reduuvidae & 0,1 & 0 & 0,3 & 0 & 0 \\
Tettigonidae & 15 & 15,2 & 8,3 & 11,6 & 8,6 \\
Staphylinidae & 0,4 & 0,4 & 0,1 & 1 & 1,4 \\
Carabidae & 0,1 & 0,2 & 0,6 & 0,3 & 0,2 \\
Coccinellidae & 15,4 & 13,4 & 13,1 & 19,8 & 21,4 \\
Coenagriodae & 3,8 & 2,1 & 1 & 2,5 & 3,8 \\
Mantidae & 0 & 0,1 & 0 & 0 & 0 \\
\hline
\end{tabular}

Tabel 3. Populasi arthropoda parasitoid berdasarkan famili

\begin{tabular}{lccccc}
\hline \multirow{2}{*}{ Famili } & \multicolumn{5}{c}{ Populasi parasitoid tiap plot pengamatan } \\
& (ekor) & \\
\cline { 2 - 6 } & Plot 1 & Plot 2 & Plot 3 & Plot 4 & Plot 5 \\
\hline Pipunculidae & 2,4 & 0,8 & 2,3 & 1,5 & 0,8 \\
Braconidae & 1,6 & 0,8 & 0,5 & 0,8 & 0,9 \\
Ichneumonidae & 0,2 & 0,1 & 0,1 & 0,4 & 0,2 \\
Chalcididae & 0,9 & 0,1 & 0,1 & 0,2 & 0,1 \\
Eulophidae & 0,3 & 0,1 & 0 & 0,2 & 0 \\
Trigonalidae & 0 & 0 & 0 & 0,1 & 0 \\
\hline
\end{tabular}

Tabel 4. Rata-rata arthropoda polinator, detritivor dan serangga netral pada plot pengamatan.

\begin{tabular}{lccccc}
\hline \multirow{2}{*}{ Famili } & \multicolumn{5}{c}{$\begin{array}{c}\text { Populasi Polinator, Detritivor dan Serangga } \\
\text { Netral tiap Plot Pengamatan (ekor) }\end{array}$} \\
\cline { 2 - 6 } & Plot 1 & Plot 2 & Plot 3 & Plot 4 & Plot 5 \\
\hline Anthomyzidae & 1,1 & 0,8 & 1,8 & 0,2 & 0,1 \\
Syrphidae & 0 & 0 & 0,2 & 0,3 & 0,1 \\
Tephritidae & 4,1 & 0,9 & 2,6 & 3,1 & 3,6 \\
Tipullidae & 4,2 & 2,5 & 2,4 & 4 & 9,4 \\
Muscidae & 7,6 & 13 & 10,1 & 10 & 12,3 \\
Lauxaniidae & 9,5 & 7,5 & 8,6 & 15,7 & 14,2 \\
Chloropidae & 2,8 & 3,7 & 2,4 & 6,4 & 6,5 \\
Pyrrhocoridae & 0 & 0 & 0,1 & 0 & 0,1 \\
\hline
\end{tabular}

\section{Tingkat Keanekaragaman Arthropoda}

Tingkat Keanekaragaman didapat dari penghitungan jumlah total jenis dalam suatu plot pengamatan. Nilai indeks keragaman tertinggi terdapat pada plot 1 dengan nilai sebesar 2,95, sedangkan indeks keragaman terkecil terdapat pada plot 2 dengan nilai sebesar 2,70, dengan nilai tersebut maka tingkat keragaman semua plot berada pada kategori sedang dengan kisaran angka lebih dari (>) 2 dan kurang dari (<) 3. Nilai kekayaan jenis paling tinggi terdapat pada plot 3 dengan nilai sebesar 4,55 dan terendah terdapat pada plot 2 dengan nilai sebesar 4,14. Nilai kemerataan paling tinggi terdapat pada plot 1 yaitu dengan nilai 0,85 dan nilai terendah terdapat pada plot 2 dengan nilai sebesar 0,79 (Tabel 5).

Tabel 5. Nilai keragaman $\left(H^{\prime}\right)$, kekayaan jenis (R) dan kemerataan (E')

\begin{tabular}{lccccc}
\hline & \multicolumn{5}{c}{ Nilai Keragaman, kekayaan Jenis dan } \\
\cline { 2 - 6 } Indeks & Plot & Plot & Plot & Plot & Plot \\
& 1 & 2 & 3 & 4 & 5 \\
\hline Keragaman (H') & 2,95 & 2,70 & 2,86 & 2,86 & 2,84 \\
Kekayaan Jenis (R) & 4,45 & 4,14 & 4,55 & 4,39 & 4,37 \\
Kemerataan (E') & 0,85 & 0,79 & 0,82 & 0,82 & 0,81 \\
\hline
\end{tabular}

Berdasarkan nilai keragaman, kekayaan jenis dan kemerataan maka dapat dikategorikan bahwa ratarata semua plot mempunyai nilai kemerataan yang tinggi. Nilai kemerataan yang mendekati 0 menunjukkan pada plot tersebut masih terdapat satu famili yang dominan karena nilai kemerataannya masih kurang dari nilai 1.

\section{Pembahasan}

Populasi Arthropoda yang didapat pada lahan rawa di Gumukmas sebanyak 6.834 ekor, yang selanjutnya dilakukan proses identifikasi Arthropoda sehingga terbagi menjadi 10 ordo dan 36 familia. 10 ordo tersebut terdiri dari Golongan Laba-laba, Ordo Coleoptera, Diptera, Hemiptera, Homoptera, Hymenoptera, Lepidoptera, Orthoptera, Odonata, dan Mantodea.

Persentase Arthropoda hasil pengamatan menunjukkan bahwa Ordo Diptera sebanyak 31,97\%, kemudian Ordo Orthoptera sebesar 21,5\%, Araneae sebesar $17,87 \%$, sedangkan persentase paling rendah yaitu Ordo Mantodea sebesar 0,01\%, Ordo Hymenoptera sebesar 1,13\%, dan Ordo Lepidoptera sebesar 1,30\% (Gambar 2). Tingginya persentase kunjungan Ordo Diptera pada plot pengamatan dapat diduga karena lokasi penelitian disekitar areal pertanaman padi merupakan ekosistem rawa yang sebagian besar berair. Larva-larva Ordo Diptera hidup di dalam air dan ketika sudah dewasa aktif terbang di pertanaman padi untuk mencari makan dan tempat berlindung, sehingga serangga tersebut keberadaannya berlimpah (Borror 1996). 
Arthropoda dikelompokkan berdasarkan peranannya di dalam ekosistem tanaman padi di lahan rawa yaitu Arthropoda herbivora, predator, parasitoid dan detritivor. Tabel 1 menunjukan famili Arthropoda herbivor dengan rata-rata paling tinggi yaitu famili Tetrigidae dan Cicadellidae. Dominansi dari famili Tetrigidae disebabkan vegetasi di lahan rawa yang berupa tumbuhan perdu, semak, dan rumput sehingga mempengaruhi kelangsungan hidup serangga ordo Orthoptera tersebut yang sebagian besar pemakan tumbuhan (Falahudin 2015).

Hasil menunjukkan bahwa 14 familia berperan sebagai predator. Predator merupakan organisme yang sepanjang hidupnya bebas membunuh mangsanya baik pada stadia larva maupun imago serta biasanya berukuran lebih besar daripada mangsanya (Mudjiono 2013). Populasi predator yang paling tinggi yaitu famili Coccinellidae dan famili Tetragnathidae. Famili Coccinellidae merupakan kumbang kubah dari ordo Coleoptera yang berukuran sekitar 4-8 $\mathrm{mm}$ dan berperan sebagai predator dari beberapa jenis kutu pada fase larva maupun imago (Amin 2016). Famili Tetragnathidae merupakan Arthropoda predator yang populasinya tinggi. Hasil penelitian Herlinda et al. (2014), menyatakan bahwa laba-laba famili Tetragnathidae merupakan laba-laba yang menangkap mangsanya dengan membuat jaring-jaring pada tajuk tanaman padi, sehingga jumlah kehadiran famili tetragnathidae pada saat pengamatan cukup melimpah.

Arthropoda lain yang mempunyai peran penting dalam mengendalikan populasi Arthropoda herbivor yaitu parasitoid. berdasarkan pada Tabel 3 menunjukkan bahwa terdapat 6 familia yang terdiri dari dua ordo yaitu Diptera dan Hymenoptera. Ordo Diptera yang termasuk dalam parasitoid yaitu famili Pipunculidae. Famili ini merupakan angota kelompok lalat-lalat kecil dengan kepala yang sangat besar (Borror 1996). Ordo Hymenoptera yang termasuk golongan parasitoid yaitu famili Braconidae, Ichneu-monidae, Chalcididae, Platygastridae, dan famili Trigo-nalidae. Populasi yang paling tinggi ditunjukkan oleh famili Pipunculidae dan Braconidae. Menurut Geyby dkk. (2017), parasitoid dari golongan famili Braconidae merupakan serangga yang aktif mencari dan dengan cepat dapat mendeteksi mangsanya. Jenis parasitoid lain dari Ordo Hymenoptera adalah famili Ichneu-monidae yang berperan sebagai parasitoid pada larva dan pupa dari ordo Lepidoptera juga termasuk parasitoid yang aktif mencari mangsanya sehingga di berbagai tempat sering ditemukan famili tersebut.

Jenis Arthropoda yang berperan sebagai detritivor juga banyak ditemukan pada areal pertanaman padi lahan rawa. Berdasarkan hasil penelitian dapat diketahui bahwa populasi Arthropoda detritivor ratarata mencapai diatas 20 persen disemua plot pengamatan dan diketahui terdapat 5 familia sebagai detritivor yaitu famili Tephritidae, Tipullidae, Musci-dae, Lauxaniidae dan Chloropidae. Tingginya populasi Arthropoda detritivor tersebut dikarenakan pada ekosistem lahan rawa banyak ditemukan bahan organik yang terdiri dari seresah-seresah tanaman dan kotoran hewan ternak yang belum terdekomposisi, serangga detritivor sangat berguna dalam proses jaring makanan yang ada, hasil uraiannya dimanfaatkan oleh tanaman (Cholid 2017).

Berbeda halnya dengan Arthropoda polinator yang terdapat pada ke 5 plot pengamatan. Jumlah polinator dari hasil identifikasi hanya 2 famili yang tergolong polinator yaitu famili Anthomyzidae dan Syrphidae yang termasuk dalam Ordo Diptera. Keberadaan famili Anthomyzidae dari Ordo Diptera ini disebabkan karena serangga ini merupakan serangga kelompok lalat rumput yang mempunyai ukuran tubuh sangat kecil, kadang-kadang memanjang, satu pasang rambutrambut terakhir di muka mengarah ke depan. Famili Anthomyzidae ini banyak ditemukan di ekosistem yang ditumbuhi rerumputan dan pertanaman budidaya. Fase larva hidup didalam rumput rawa atau paya dan rumput-rumput gulma lainnya (Siwi 2006). Famili Syrphidae yang ditemukan pada areal pertanaman padi lahan rawa merupakan Lalat dari ordo Diptera yang berperan sebagai polinator. Famili Syrphidae merupakan lalat-lalat bunga dengan ukuran besar yang hampir ditemukan diberbagai jenis habitat. Fase larva lalat ini merupakan predator sedangkan fase imago atau dewasa terdapat diskita bunga-bunga (Borror 1998).

Populasi Arthropoda berguna seperti kelompok predator, parasitoid, polinator, dan detritivor pada Gambar 4.3 lebih tinggi presentase kehadirannya dengan nilai lebih dari $70 \%$ disemua plot pengamatan jika dibandingkan dengan kehadiran Arthropoda herbivor sehingga mampu menekan tingginya populasi Arthropoda herbivor yang mengganggu tanaman padi di lahan rawa. Melalui peran Arthropoda berguna sebagai musuh alami hama sangat membantu petani dalam mengendalikan hama. Tingkat keragaman jenis serangga antara Arthropoda berguna dan herbivor memiliki dampak yang sangat penting bagi kestabilan di dalam suatu ekosistem. Semakin tinggi keanekaragaman serangga herbivor yang ada pada suatu ekosistem, maka dapat dimungkinkan semakin tinggi juga keanekaragaman parasitoid dan predator. Hal ini berkaitan dengan terpenuhi dan tercukupinya makanan bagi musuh alami tersebut (Sumarmiyati 2019).

Indeks keanekaragaman Arthropoda (H') pada semua plot pengamatan menunjukkan kategori sedang yaitu berkisar antara nilai 2,70 sampai 2,95. Besarnya nilai keragaman tersebut diduga karena di beberapa plot pengamatan hanya didominasi oleh beberapa ordo saja, seperti Ordo Orthoptera, Diptera, Coleoptera, dan Laba-laba. Menurut penelitian Wijaya (2014), menyatakan bahwa nilai keanekaragaman $\left(\mathrm{H}^{\prime}\right)$ di pengaruhi oleh tingginya nilai variasi ekor dan jumlah spesies, jika nilai variasi populasi Arthropoda rendah/kecil atau habibat hanya didominasi oleh beberapa spesies, maka nilai keragaman yang didapat (H') akan semakin kecil.

Kekayaan jenis (R) memiliki nilai yang berbeda dengan kisaran angka antara 4,14 sampai 4,55 yang menunjukkan bahwa tingkat kekayaan jenis pada plot pengamatan tinggi dengan kriteria $\mathrm{R}>4$. Hal ini diduga 
karena pada areal pertanaman padi dengan ekosistem rawa menjadikan lingkungannya mendukung untuk berkembangnya Arthropoda herbivor dan juga dijadikan sebagai inang alternatif bagi Arthropoda berguna atau musuh alami. Hal ini dapat dilihat pada Gambar 3 bahwa populasi Arthropoda predator lebih tinggi populasinya dibandingkan Arthropoda herbivor. Berdasarkan nilai Indeks Kemerataan Jenis (E') dapat disimpulkan bahwa komu-nitas hampir merata pada semua plot pengamatan karena kisaran angka yang ditunjukkan memiliki nilai diatas 0,79-0,85. Semakin kecil nilai E' atau mendekati nol, maka penyebaran suatu organisme tidak merata atau dalam suatu komunitas tersebut didominansi oleh jenis tertentu (Kartikasari dkk. 2015).

Populasi Arthropoda yang ditemukan pada lahan rawa di Gumukmas sebanyak 6.824 ekor yang terdiri atas: golongan Arachnida (Laba-laba), Ordo Coleoptera, Diptera, Hemiptera, Hymenoptera, Homoptera, Lepidoptera, Odonata, Orthoptera dan Mantodea yang peranannya pada ekosistem sebagai herbivor sebesar $25 \%$, Predator 47\%, Parasitoid 2,3\%, Polinator 0,6\% dan detritivor sebesar 24,4\%. Komposisi Arthropoda yang berupa herbivor, predator parasitoid, polinator dan detritivor pada areal pertanaman padi lahan rawa cukup seimbang dengan tingkat keanekaragaman $\left(\mathrm{H}^{\prime}\right)$ 2,70 - 2,95 yang termasuk dalam kategori sedang dengan tingkat kemerataan (E) sebesar 0,79-0,85 yang termasuk dalam kategori tinggi.

\section{Pernyataan tidak ada konfik kepentingan}

Semua penulis artikel ini menyatakaan bahwa tidak ada konflik kepentingan terkait penelitian dan hasil penelitian ini.

\section{DAFTAR PUSTAKA}

Amin A, Ibrohim, Tuarita H. 2016. Studi keanekaragaman arthropoda pada lahan pertanian tumpangsari untuk inventarisasi predator pengendalian hayati di Kecamatan Bumiaji Kota Batu. Pertanian Tropik, 3 (2): 139-149. DOI: 10.32734/jpt.v3i2.2968

Borror DJ. Triplehorn C.A \& Johnson NF. 1996. Pengenalan Pelajaran Serangga Edisi Keenam. Partosoedjono S, penerjemah; Brotowidjoyo MD, editor. Yogyakarta: Gadjah Mada University Press. Terjemahan dari: An Introduction to The Study of Insects

Borror DJ, White RE. 1998. Insect: Peterson Field Guide. Houghton Mifflin Harcourt, Mexico.

Badan Pusat Statistik. 2018. Luas Panen, Produksi, dan Produktivitas Padi Menurut Provinsi 2018. Badan Pusat Statistik, Jakarta.

Bismark M. 2011. Prosedur Operasi Standar (SOP) untuk Survei Keragaman Jenis pada Kawasan Konservasi. Pusat Penelitian dan Pengembangan Perubahan Iklim dan Kebijakan, Badan Penelitian dan Pengembangan Kehutanan, Bogor.
Cholid I. 2017. Keanekaragaman Serangga Aerial pada Perkebunan Teh PTPN XII Wonosari Kabupaten Malang. Skripsi. UIN Maulana Malik Ibrahim. Malang

Falahudin I, Mareta DE, Rahayu IAP. 2015. Diversitas Serangga Ordo Orthoptera pada Lahan Gambut di Kecamatan Lalan Kabupaten Musi Banyuasin. Bioilmi 1 (1): 1-7. DOI: 10.19109/bioilmi.v1i1.1124

Herlinda S, Manalu HCN, Aldina RF, Suwandi, Wijaya A., Khodijah, Meidalima D. 2014. Kelimpahan dan keanekaragaman spesies laba-laba predator hama padi ratun di sawah pasang surut. J HPT Tropika 14 (1):1-7. DOI: 10.23960/j.hptt.1141-7

Geyby K, Tulung M, Salaki CL. 2017. Jenis-jenis serangga yang berasosiasi pada eceng gondok di Danau Tondano. Agri-Sosio Ekonomi 13 (3): 133-142.

Kartikasari H, Heddy YBS, Wicaksono KP. 2015. Analisis biodiversitas serangga di hutan Kota Malabar sebagai urban ecosystem services Kota Malang pada musim pancaroba. Produksi Tanaman 3 (8): 623-631.

Mudjiono G. 2013. Pengelolaan Hama Terpadu: Konsep, Taktik, Strategi, Penyusunan Program PHT, dan Implementasinya. Universitas Brawijaya Press. Malang.

Purwantiningsih B. 2014. Serangga Polinator. Universitas Brawijaya Press. Malang.

Sumarmiyati FH, Sundari. 2019. Keragaman serangga pada pertanaman padi sawah di Kabupaten Kutai Kartanegara Kalimantan Timur. Prosiding Seminar Nasional Biodiversitas Indonesia 5 (2): 217-221.

Wijaya N. 2014. Analisis komposisi dan keanekaragaman spesies tumbuhan di hutan Desa Bali Aga Tigawasa, Buleleng-Bali. J Sains dan Teknologi 3 (1): 288-299. DOI: $10.23887 /$ jstundiksha.v3i1.2907

Yursida, Kalsum U. 2015. Observasi hama penyakit dan musuh alami hama padi di Desa Telang Karya Kabupaten Banyuasin. Proseding Seminar Nasional Lahan Suboptimal, ISBN 979-587-580-9. Palembang. 